\title{
Discussion of Current Situation and Measures of Development Dalian Amateur Volleyball Clubs
}

\author{
Cao Mingming Gao Qin* \\ (Sports College of Dalian University, Dalian, Liaoning 116622)
}

\begin{abstract}
:
The development Dalian amateur volleyball clubs has just started. The research on amateur volleyball clubs is still inadequate and there exist problems in club operation and organization. This research expects to contribute to a faster and healthier development Dalian amateur volleyball clubs and to provide experience for other regions and development of other sports events.
\end{abstract}

Keywords: Dalian; Amateur; Volleyball Clubs; Current Situation

\section{Preface}

Athletic clubs are primary-level organizations in which people autonomously united on the basis of their own free will, mutual help and mutual benefit, participating in sports activities collectively. ${ }^{[1]}$ With the development of social economy in our country and the step-by-step improvement of people's income level, physical and mental health has become one of their goals to be pursued after material life demands have been satisfied. In recent years, foreign fitness clubs have made a fast development. Along with the steadily increase of demand for fitness activities among the public, the potential of development of fitness clubs is enormous in China. This development is also an emergent task, especially that of non-profit amateur fitness clubs. ${ }^{[2]}$ Currently, with the increase of social material wealth, there is more and relatively concentrated leisure time for people, which lays the foundation for development of sports industry. The amateur volleyball club, as a nongovernmental and non-profit sports organization, has obtained soaring development during this time. Compared with public sports venues organized by the government, it has more pertinence, flexibility. It enables to meet the demand of volleyball enthusiasts in society and avoids the waste of sports resources. Relative to commercial sports service venues, it is cheap and suitable for the income level of most residents in Dalian. Therefore, there is inevitability of its development. $^{[3]}$

With rapid development of fitness clubs is every regions, higher requirements have raised for the healthy and fast development of amateur volleyball clubs. At present time as well as a long time in the future, China and the whole world face economic predicament. Under the circumstances, how to make a

Fund Program: The phasic research result of Liaoning College Students' Innovation and Entrepreneurship Training Program (No.: 201211258008); Funded by educational reform fund of Dalian University (2010);

Information of author: Cao Mingming (1991-). Female. From Anshan, Liaoning. Undergraduate;

Corresponding author: Gao Qin (1971-). Female. Lecturer. Postgraduate. Working on sports education and 
training. E-mail: gaoqin_2006@126.com. steadfast step of healthy development becomes the main strategy. Therefore, it is necessary to make a rigorous survey and research on the current development situation of Dalian corresponding measures so as to enhance the Dalian as well as China. amateur volleyball clubs according to the present condition of China and to implement healthy and stable development of and the value realization of amateur volleyball clubs in

2.1 Current Situation of Club Members

\section{Basic Information of Dalian Amateur}

Volleyball Clubs

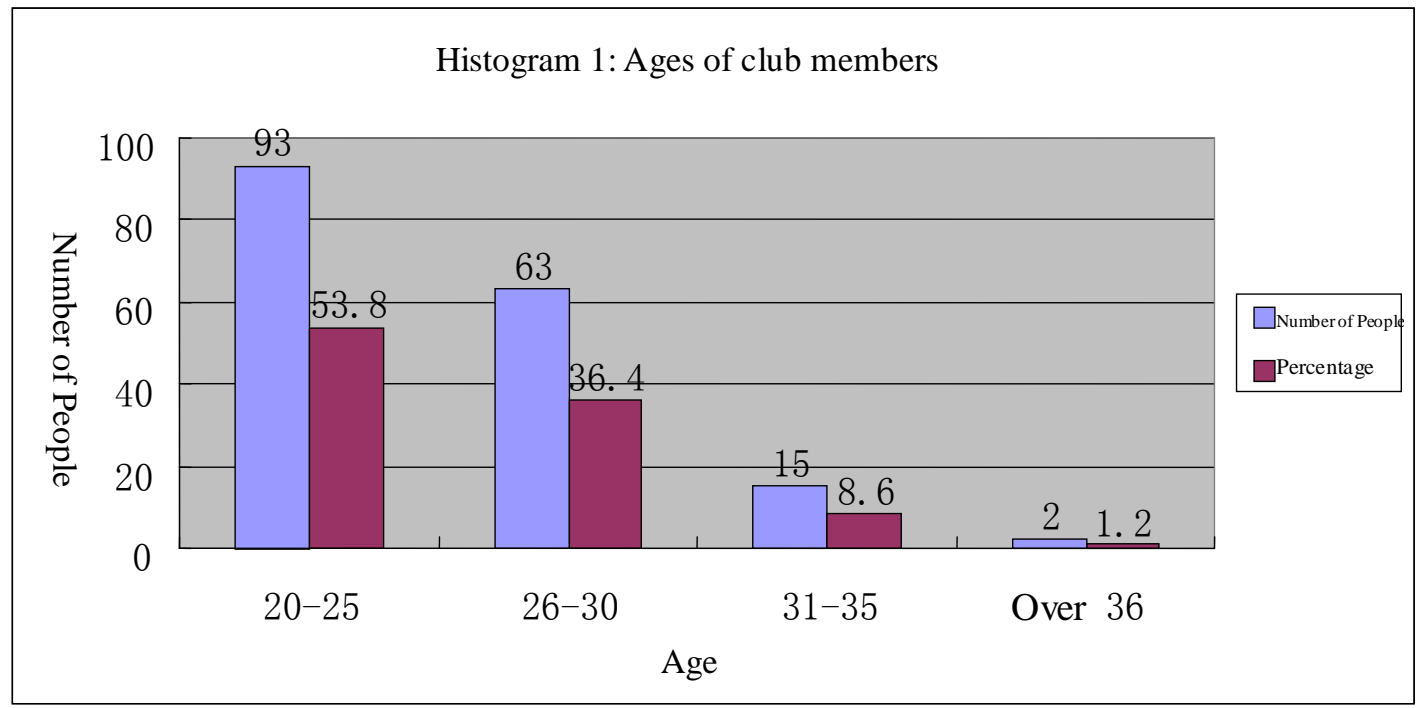

Histogram 1 shows that ages of most club members surveyed range from 20 to 30, which accounts for $90.2 \%$.Middle-aged members over 30 years old account for only $9.8 \%$ of the respondents. Even though half of the surveyed members come from amateur volleyball clubs of universities, most members of social clubs age from 26 to 30 and few are above 30 years old. Statistics show that core force of Dalian amateur volleyball clubs is youth, which is possibly related to the physiological and psychological characteristics of young people. Students in colleges and universities have less

Histogram 2 shows the statistics of education background of clubs members. $97.7 \%$ are undergraduates or above, which indicates that the overall cultural quality of members of Dalian amateur volleyball clubs is high. This fact lays a good foundation for only several universities which have set up learning burden than those in high schools; they are full of energy and courage to bring forth new ideas, focusing on social interaction. Besides, the careers of the young people in society of the amateur volleyball club just begin to be stable; these young people have plenty of spare time and rich cultural life with wide social interaction and fitness consciousness. Participating in the sport can bring them the delight that cannot be experienced in other activities. It is the youth that inject vigor into development of amateur volleyball clubs.

further development of amateur volleyball clubs.

In addition to the above three graphic display of the data on age, educational background and profession, they are currently

girl's volleyball clubs among the amateur 
volleyball clubs in Dalian. Furthermore, none of them has participated in any major match but the games held in the school and they have little communication with the outside world. There are few female athletes in the amateur volleyball clubs of the social group. The reason may be attributed to the burden of the family factors; women not only play the social role, but also an important role of the family.

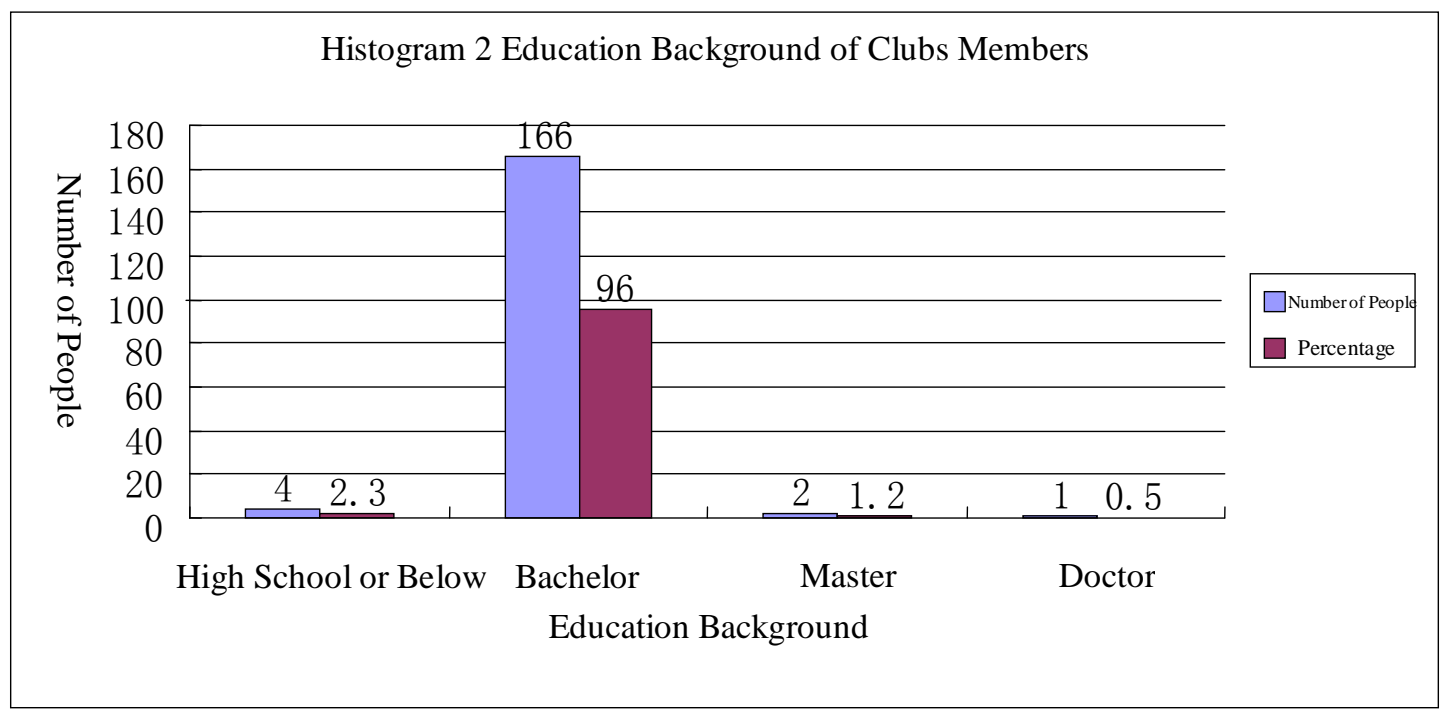

According to Chart 3 that shows the professions of club members, members of university clubs are mainly students in colleges and universities, and members of social clubs come from a variety of professions mainly including enterprise personnel and government officers and public institution officers. This fact may be related to their relatively higher income and more leisure time

Pie Chart 3 Occupations of Club Members

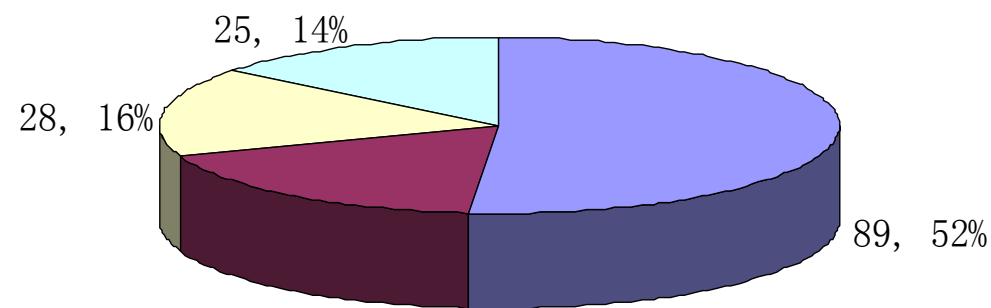

$31, \quad 18 \%$

2.2 Factors Affecting the Development of Dalian Amateur Volleyball Clubs

According to statistics, main factors affecting the development of Dalian amateur volleyball clubs are 
shown in Table 1.

Table 1: List of Factors Affecting the Development of Dalian Amateur Volleyball Clubs

\begin{tabular}{llllll}
\hline & $\begin{array}{c}\text { Very } \\
\text { impact }(\%)\end{array}$ & $\begin{array}{l}\text { big } \\
\text { impact } \\
(\%)\end{array}$ & $\begin{array}{c}\text { Moderate } \\
\text { impact } \\
(\%)\end{array}$ & $\begin{array}{c}\text { Small } \\
\text { impact } \\
(\%)\end{array}$ & No impact (\%) \\
\hline $\begin{array}{l}\text { Overall management of } \\
\text { Sports Departments }\end{array}$ & 48 & 34 & 11 & 7 & 0 \\
Club fund & 52 & 36 & 10 & 2 & 0 \\
support of social enterprises & 32 & 42 & 17 & 5 & 4 \\
Sports instructor & 32 & 20 & 25 & 16 & 7 \\
activity venues & 56 & 35 & 7 & 2 & 0 \\
\hline
\end{tabular}

\subsubsection{Management of Related Sports}

\section{Departments}

According to survey result, currently few Dalian amateur volleyball clubs are registered in related sports department except for minority of university amateur volleyball clubs. The phenomenon results in the lack of overall management of amateur volleyball clubs by related sports department, lack of mechanism and regulations, and an unorganized condition. This is harmful for future development.

\subsubsection{Club Fund}

Currently, the amateur volleyball club is a public sports organization established according to individual interest with a small scale, and belongs to non-profit organization; therefore it cannot sustain its activities by business like enterprise units. Besides, it is a kind of nongovernmental organization that cannot receive sports subsidy from related departments, so the club has to rely on membership fees. Shortage of fund to a great extent restricts the training organization and match participation of the club. Most of the games are unofficial and for the sake of communication between clubs; there are few opportunities to participate in the nationwide games held by amateur volleyball clubs. To sum up, the improvement of the amateur club level has been greatly impacted to some degree. [4]

\subsubsection{Support of Social Enterprises}

Table 1 shows that $74 \%$ of respondents acknowledge the great influence of social enterprises on future development of Dalian amateur volleyball clubs. This is mainly because social enterprises can support clubs financially and in return obtain advertisement effect. This is a win-win benefit. In the survey, members of every association believe that their own amateur volleyball club is short of funds which come from the membership fees and AA payment mode assumed by each member. As a result, they can only recreate by themselves and every amateur volleyball club hardly participates in or studies professional games or other games that is a little bit influential. The development of amateur volleyball clubs is inevitably limited.

\subsubsection{Sports Instructor}

Table 1 shows that $52 \%$ of respondents acknowledge the influence of sports instructors on development of clubs. $41 \%$ of them don't recognize a big impact of sports instructors, and $7 \%$ think sports instructors have no influence. On one hand, there is a shortage of sports instructors in society. Most professional volleyball coaches work in schools, professional teams, professional sports school, etc. Amateur clubs are mainly aimed at fitness and entertainment with low requirements for professionalization, so most respondents don't acknowledge the big impact of sports 
instructors on clubs.

\subsubsection{Activity Venues}

There is no high requirement for volleyball courts. An open space is enough for digging or training. In reality, field and equipment is an essential material base for developing volleyball activities; survey suggests that $91 \%$ of respondents think volleyball venues have big and even great impact on development of clubs. This shows that the limit of site facilities is one of the reasons why volleyball activities cannot develop. If the amateur club is short of necessary activity space or equipment, be it in training or in games, the development of the volley club will be greatly affected

\section{Conclusion and Recommendation}

There are no related sports departments regulating and supervising the development of Dalian amateur volleyball clubs.

Currently, the organization and management of Dalian amateur volleyball clubs lack standardization.

Problems of shortage of management fund and of activity venues are comprehensive.

There is a shortage of volleyball instructors. 3.2 Recommendations

As to the lack of standardization of development of Dalian amateur volleyball clubs, it is recommended that related sports department should manage comprehensively the development of amateur volleyball clubs, establish wholesome organization and management mechanism and enhance Dalian amateur volleyball clubs to become standardized gradually.

Due to the nonstandard organization and management of Dalian amateur volley ball clubs, it is recommended that the management of amateur volleyball clubs should be standardized and that the relevant supervisory mechanism should be established to guarantee the normal operation of the normal organization and management of the activities held by the clubs.

Due to the lack of professional coaches and sports instructors for Dalian amateur volleyball clubs, it is recommended that clubs should cooperate with sports schools that provide professional instructors for clubs. This cooperation also relieves the employment pressure and solves the problem of venues to some degree.

\section{References}

[1] Li Hong and Li Hebiao. "An Investigation and Analysis of the Development Status of Am ateur Volleyball Clubs in Anhui" [J]. Journal of Chifeng University, 2011 (7): 184-186.

[2] Wang Lixiao, Zhou Xuebin, Li Jia. "Research of Current Situation and Measures of Development Nanjing Amateur Volleyball Clubs". Sports Worlds Scholarly, 2007 (1): 40-41.

[3] Bao Qiang. “Analysis of Current Situation and Measures of Development Nanjing Amateur Volleyball Clubs" (postgraduate academic dissertation). Hubei: Central China Normal University, 2008. [4] Bi Zhuo. "The Exsiting Problems of Amate ur Volleball in the Colleges and Universities o f Hunan and Recommended Solutions" [J]. Sp orts World, 2012 (4): 55-56. 